\title{
Insurance for autonomous underwater vehicles
}

\section{G GRIFFITHS}

National Oceanography Centre, Southampton, UK, SO14 3ZH

Tel: +44 (0) 2380596004 Fax: +44 (0) 2380596149 gxg@noc.soton.ac.uk

\section{N BOSE}

Canada Research Chair in Offshore and Underwater Vehicles Design, Faculty of Engineering and Applied Science, Memorial University, St. John's, Newfoundland, Canada, A1B 3X5 Tel: +1 7097374058 Fax: +1 7097376184 nbose@engr.mun.ca

\author{
J FERGUSON \\ International Submarine Engineering, 1734 Broadway St., Port Coquitlam, B.C., Canada, \\ V3C 2M8 Tel: +1 6049425223 Fax: +1 604 942-7577 james.ferguson@ise.bc.ca \\ D R BLIDBERG \\ Autonomous Undersea Systems Institute, 86 Old Concord Turnpike, Lee, New \\ Hampshire 03824 USA Tel: +1 6038683221 Fax: +1 6038683283 ausi@ausi.org
}




\section{Abstract}

The background and practice of insurance for autonomous underwater vehicles (AUVs) are examined. Key topics include: relationships between clients, brokers and underwriters; contract wording to provide appropriate coverage; and actions to take when an incident occurs. Factors that affect cost of insurance are discussed, including level of autonomy, team experience and operating environment. Four case studies from industry and academia illustrate how AUV insurance has worked in practice. The paper concludes by stressing the importance of effective dialogue between client, broker and underwriter to review, assess and reduce risk to the benefit of all parties.

Keywords: Autonomous underwater vehicles, risk, insurance

\section{Introduction}

Managing risk is essential to the effective use of autonomous underwater vehicles (AUVs) in marine science, industry and defence applications. One option for managing risk is to transfer it to, or to share it with, others. On a commercial basis, this is achieved through taking out insurance and paying a premium. This option is usually taken either because the owner/operator cannot afford to take the loss, or because the law requires it (not the case currently with AUVs), or because the funding agency for the vehicle makes it a condition.

Over the last decade, increasing use has been made of commercial insurance by marine science and commercial operators of AUVs, through several brokers and 
underwriters. There is a greater awareness today of risk management among owners and users than when Edwards described the process and the actors ${ }^{1}$. At that time (2000) almost all of the insured vehicles were operated by designers and constructors. In the recent past, as more vehicles are sold to operators, the risks have changed; and as insured vehicles have been lost, severely damaged, or required expensive retrieval, the cost of AUV insurance has increased as underwriters are in business to make profit.

This paper explores the relationships between the client seeking insurance for an AUV, the insurance broker, and the underwriter of the risk. It also outlines what might happen following a claim and discusses a number of factors that might affect the cost of insurance for an AUV. To illustrate these points we present four case studies: two from experienced developers and users, one from a new user in the research community and one from an experienced user in the offshore industry.

\section{Relationships between client, broker and underwriter}

Having a clear understanding of the chain of relationships from the client (the purchaser of insurance) to the underwriter is important in this specialised and still-developing business. The exact relationships may be different in different countries; the description here pertains to the UK.

In theory, it is possible for a client to go directly to the underwriting markets to obtain insurance. However, via this route the client has no guarantee of finding the best value. The issues are complex, and we consider it important to have a broker or insurance professional to advise on the types of cover, what they actually provide, and in the event of a claim to represent the client's interests. 
A professional insurance broker is the agent of the client and will need to develop an understanding of the client's AUV operations in order to best represent their interests and to ensure that the cover bought is the best value. While the broker may well approach an underwriter directly, he may also work through a more specialized broker or binding authority to locate the best value in the insurance market. To our knowledge there are only two appropriately specialist marine insurers or underwriters, for the reason that others simply do not care to take on the risk in this sector.

There is, however, a choice of insurance markets. Lloyd's of London is a specialist insurer capitalized by some of the largest financial companies. One alternative to the Lloyds marketplace, the companies market, can be accessed to provide insurance. However, as a broad generalisation, the companies market is predominantly concerned with actuarial risks e.g. life insurance, rather than the more specialized risks handled through Lloyds. The companies market may well provide AUV insurance if it becomes bundled with more general insurance for an organisation.

In practice, AUV insurance has been placed with the Lloyds and companies markets.

\subsection{Importance of appropriate wording in an AUV insurance contract}

AUVs are complex. They are also intended for use in unusual or hazardous conditions. It is therefore most important that the wording of the insurance contract for an AUV provides the coverage that the client requires. That protection may need to cover several situations, including damage or loss whilst:

- On land - in storage, and if the vehicle is being launched and recovered from shore.

- While being transported, by land, sea or air. 
- While being maintained, modified or upgraded.

- While in operation, including launch and recovery, monitored transit and unattended operations.

To ensure that the wording meets the client's requirements, the underwriter may meet with the client to understand first-hand their business, their operation and the likely risks. Such an understanding may be supported by detailed documentation on procedures and risks of the types of missions to be undertaken. Based on this first-hand understanding, the underwriter may not need to receive further details of operational schedules if use is within agreed parameters.

Other coverages include:

- Third party liability: This is an interesting area as the legal status of an AUV is not clear $^{2}$, therefore the statutory requirements for third party liability and how the courts would view any incident are likely to be taken on a case by case basis.

- Consequential damages: This covers financial loss caused by failure to perform or the business interruption caused by an incident. Such cover is very likely to be hard to find due to the prototypical nature of many AUVs.

\subsection{When it comes to making a claim}

The first response to an incident that may result in a claim is for the client to "act as a prudent uninsured" in the steps that are taken. If the vehicle is lost, there has to be a cutoff point, for example, on the time (and hence money) spent on searching. There may be a conflict if, for example, the client places a high value on retrieving the data in the AUV, but the data is uninsured or the re-survey costs would not be covered. 
Underwriters outsource claims to an adjuster to avoid conflict of interest. The services of the loss adjustor are provided at the expense of the underwriter. In the case of damage, the adjuster may survey the vehicle, check that the claim falls within the scope of the insurance, and examine the options with the client to put the vehicle back into the condition it was in before the incident (for an indemnity policy), unless the insurance was on a betterment or new-for-old basis.

Soon after a claim has been lodged, the underwriter will table the total costs of the claim, including all fees. It is not in the interest of any of the parties to the insurance to delay payment as the cost has been reserved early in the process. The record of the client will show the loss against premiums paid; it will not include professional fees.

If the client chooses not to restore or repair the AUV, but instead chooses to take money, the claim becomes one for "unrepaired damage". The market rate for unrepaired damage claims is less than $100 \%$ (fair market value) and the policy will also have a deductible. Hence the cash returned will be significantly less than the full value of the AUV.

It may be that when a vehicle is lost, the client may have suitable equipment to effect a recovery, for example an ROV with an experienced support team. Under a sue and labour clause, the client will be able to claim for the additional costs incurred in locating and retrieving the AUV, for example the additional labour and fuel. The policy will have been priced on this understanding.

If an incident occurs that is within the deductible on the policy, especially for a newly insured AUV, the underwriter may suggest that a loss adjustor look at the case to exercise the process and possibly identify any improvements that may be necessary. 


\subsection{Factors that may affect the cost of insurance}

Among the factors that are likely to affect the cost of insurance for an AUV are:

- Experience, track record, qualifications and training of the staff involved with the AUV. This would include the technical support and engineering staff and those involved in launch and recovery and mission planning. Specific training of staff by the AUV manufacturer is an asset.

- Vessel operators involved in launch and recovery - their experience and track record, together with the characteristics of the support vessel.

- Evidence of clear risk assessments, checks and controls in operating procedures.

- Evidence of risk mitigation measures. These might include technical measures, such as homing and emergency beacons and procedural measures such as maximum allowed sea states for recovery.

- Details of the operating environment and its specific risks.

- The extent of co-insurance between the underwriter and the client. For example, during launch and recovery operations, the vehicle might be co-insured. If damage is sustained, then the claim is split on a previously-agreed basis, and the claim is settled for the balance, less the deductible.

\section{Case studies}

These case studies cover different experiences with AUV insurance through several brokers, binding authorities, underwriters and insurance companies. 


\subsection{Autosub - National Oceanography Centre, Southampton, an established developer and user for research}

The National Oceanography Centre, Southampton has been operating and insuring its Autosub series of science research AUVs since 1996. Previously, as the Institute of Oceanographic Sciences*, it had been the practice and policy to insure oceanographic equipment of high value where it made demonstrable economic sense. In other words, as part of a risk management strategy, commercial insurance would be considered attractive if it could be shown to mitigate the impact of risk or protect core budgets from large losses at reasonable premiums. As a consequence of a long track record of insuring highvalue oceanographic equipment, when it came to insuring our first AUV we had both the contacts and track record. Risk management has been at the heart of the Autosub programme from the start, and no more so than in the issues and uncertainties on international, public and private law that surround $\mathrm{AUVs}^{2,3}$.

In 1995, with the transfer of management to the University of Southampton, we moved to an organisation where commercial insurance was the norm. However, rather than attempt to include our subsea equipment within the insurance package of the university, it was agreed with the university that we would continue with the specialised insurance policies that had served us well in the past.

While the brokers that we have bought insurance through have changed over the years, the underwriter has remained the same. This has enabled us to establish a close liaison, which helps the underwriter understand the risks with AUVs in science research. The insurance package covers damage to the vehicle in use and in transit and it covers

\footnotetext{
* Part of the UK Natural Environment Research Council (NERC), a non-departmental public body.
} 
third party liability. Since 1996 we have made two substantial claims resulting from the temporary stranding subsea of Autosub. In each case matters were dealt with swiftly and without any dispute. Both involved the hiring of offshore ROV support vessels, one for a recovery from under an overhang on a cliff in the Strait of Sicily (Figure 1a) and one from a muddy seabed in the SW approaches to the UK (Figure $1 \mathrm{~b}$ and c).

$<$ Figure 1 near here $>$

There have been rare occasions on which having insurance has led to some complications. For example, when the AUV was to be deployed from a UK publiclyowned but privately-operated vessel. The operator was concerned that, if damage to Autosub was sustained during launch or recovery, and an insurance claim was made by us, then our insurer would make a claim against them. While they were insured, they had a substantial deductible, and the private operators wanted to be clear who would carry responsibility for their deductible should an accident happen. The solution was for us to use our best endeavours to obtain the formal consent of our underwriter to name and add the owners, managers and crewing agents of the vessel as additional assured under our policy for Autosub and that the underwriters waive their rights of subrogation against them, and reciprocal naming by the insurers of the vessel. In addition both parties agreed to an indemnity clause based on the wording of a clause in the BIMCO Supplytime charter agreement (see www.bimco.dk/upload/supplytime 2005web.pdf).

AUV missions under sea ice in 2001 were covered by insurance at an acceptable premium. When missions under shelf ice were being planned, a thorough analysis was

\footnotetext{
* Shelf ice is the floating part of continental ice sheets, e.g. in Antarctica and Greenland. It is formed from snowfall, it is essentially continuous and can be several hundred meters thick, In contrast sea ice is formed at sea, is usually less than $10 \mathrm{~m}$ thick, is often discontinuous and is navigable using icebreakers.
} 
made of the risk and reliability of the vehicle ${ }^{4}$. This report was passed to the underwriters to ensure that they were fully briefed as to the risks from the environment and the risk from failure of any of the vehicle systems. It was the conclusion of the report that it was more likely than not, over the three campaigns envisaged, that the Autosub would be lost. Perhaps surprisingly, the underwriter did not turn down the potential business.

The premium quoted was, however, substantial, and, even though an offer was made to return part of the premium at the end of each year of insurance if the vehicle was not lost, we could not justify the cost. A factor in this decision was that if insurance was taken out, and the vehicle was lost, there would be at least a year's interregnum while a replacement vehicle was built and tested. Notwithstanding this decision, the insurance agreement remained in place, and an acceptable premium paid for all of the periods of engineering trials in open water, for third party liability during these trials and for damage or loss of the vehicle during transit to the working area.

Armed with the underwriters' offer we approached the funding agency (NERC) and reached an agreement that the Autosub Under Ice (AUI) programme would receive funding up-front to build and commission a second Autosub within the programme. The intention was that there would be a replacement vehicle available in time for operations in the next polar season. In essence, this was a form of self-insurance; one that had the advantage of ensuring that the gap between loss and replacement would be shorter than had the underwriters' offer been taken up. As it turned out, the prediction became true Autosub was lost on the third campaign of the AUI programme ${ }^{5}$ Through this selfinsurance arrangement the replacement was at sea on its trials five months after the loss covered by insurance. 


\subsection{Company Y: an industry user of AUVs}

With the advent of corporate consolidations, small companies see themselves at a disadvantage when buying insurance. They simply cannot afford the insurance clubs that require significant deductibles and the high degree of risk exposure if claims do not come in as expected. Today there are very few excess carriers in the world that will insure these underwater vehicles. This is different to the case in the past with conventional towed geophysical or seismic equipment where there was more choice, and hence more competition. If one operator loses one or more AUVs, as does happen, others see costs rise and issues emerge at their next premium renewal. Some in the commercial world do not see their underwriter putting more emphasis on experience when assessing premiums. For example, in one instance, after an underwriter paid a claim by company $\mathrm{X}$ due to a problem with part of their particular system they put a $\$ 1 \mathrm{~m}$ deductible on the functionally similar, but completely different sub-system of company Y. Company Y was not asked to supply information about their experience, nor information about the differences in their sub-system compared to that of company X.

The biggest complaint is of the underwriter who needs to understand our business, to better rate the risk, depending on written material and what the broker or agents know about the company. In many cases this can be second or third hand information; almost inevitability the message may be inaccurate. The long line of commissions involved (three or four not being unusual) gets most criticism. This breeds frustration; one Chief Financial Officer, convinced that this chain hampers rather than eases his insurance had the message, "move out the way so I can explain my business to the underwriter". 


\subsection{International Submarine Engineering (ISE), Canada, a developer and} supplier

ISE has been in the business of developing and selling underwater vehicles since 1974, delivering over 200 vehicles to clients. With all of these vehicles, builder's and sea acceptance trials form part of the contractual agreement between the company and the client, and responsibility remains with the company until the client accepts the vehicle. By the time sea trials occur, the client has deposited substantial funds against the delivery of the vehicle and the company is obligated to cover this investment, either by selfinsuring or by obtaining insurance coverage. Generally, the high cost of underwater vehicles compared with the relatively low cost of short-term coverage from an underwriter has made the latter alternative more attractive. It should also be noted that this coverage normally includes a "Sue and Labour" clause that offsets the cost of locating and salvaging an underwater vehicle.

Over the years, the annual rates for this coverage have varied, starting from 3\% of capital cost for tethered vehicles and 6\% for AUVs in the 1970s and 1980s to a high of $12 \%$ for AUVs today. For these short-term trials, we are able to purchase this insurance on a pro rata, monthly basis.

In over thirty years of operating ROVs, AUVs and other underwater vehicles, ISE has made a total of three claims. Two of these have been AUVs in which major damage was sustained (over $30 \%$ of vehicle cost). The third involved major damage to a tow fish. In all of these cases, our claim was dealt with in a professional and expedient manner. Because our trials are usually conducted from the same vessel, in the same location and with the same operators, the risk associated with our operation is well understood by the 
broker and the underwriter and our rates have remained fairly stable. In only one instance was there an increase that could be directly related to a claim by the company.

In the 1990s, we began development of an under-ice cable-laying vehicle with the Canadian Department of National Defence (DND). This AUV (Theseus) was required to deliver $220 \mathrm{~km}$ lengths of underwater cable to remote sites under Arctic sea ice and then return to an under-ice base station ${ }^{6}$. These missions, up to $450 \mathrm{~km}$ in length, remain among the longest AUV missions conducted to date.

We recognized that the cost of insurance for this project was going to be an important factor for DND; consequently, during the initial design stages we approached the underwriters. Because of our inexperience in presenting a low risk scenario, we received the disappointing and unacceptable news that the upfront premium would be $100 \%$ of the value of the vehicle, with a $50 \%$ rebate should we complete the mission without making a claim.

Over the next two years, the programme team worked closely with the broker to mitigate the risk as seen by the underwriter, involving: vehicle design, pre-deployment testing, and the planning and conduct of on-ice operations. In the design of the vehicle, increased attention was given to component reliability, the possible use of redundant systems or components, and the development of new equipment such as obstacle avoidance sonars. Also, in addition to the buoyancy compensation system for the cable, a variable buoyancy system was added to the vehicle. More emphasis was placed on the accuracy of the vehicle's navigation throughout the mission, rather than simply at the end points (homing). Finally, anything relating to location - acoustic transponders, the paint 
scheme, the use of reflective tape - and recovery - vehicle power-on switch, lift points and other attachments schemes, received close scrutiny.

To further mitigate risk, extensive sub-system and system testing was conducted ${ }^{6}$ in 1994 and 1995, and prior to mission deployment in 1996 two complete missions were conducted in open water on the Canadian Forces Maritime Experimental Test Range in Nanoose, BC. Finally, the operations planning was reviewed to provide the contingency for lost vehicle operations at any stage of the mission. A helicopter was already part of the logistics plan, but an ROV was provided to attach recovery lines at the under-ice base, and to facilitate recovery operations in the event of a loss. Finally, portable equipment necessary for making holes in the ice and operating the ROV at remote sites was included.

Several weeks before the mission deployment was scheduled to start, we received news of the final decision from the underwriter - that under-ice operations would be covered at $1 \%$ of capital cost with a $\$ 25,000$ deductible and a total of $8 \%$ premium should the vehicle be lost and not recovered (i.e total loss).

During the last operation in the Arctic, Theseus laid its cable successfully, but did not show up at the mid-point rendezvous on its return journey. The search plans were put into place, and after two days, the vehicle was located on the bottom and on its planned track. An error in failsafe programming had caused the vehicle to shutdown and sit on the bottom. Once found, it became a relatively simple matter to rectify the problem and send the vehicle on its way back to the ice-camp. 
This case clearly highlights the value of planning for insurance coverage in the design and operation of AUVs. Without this planning, ISE would have faced a premium of several million dollars and a significantly higher probability of a loss.

\subsection{Memorial University, Canada, a new academic user}

In the preparations for acceptance and commissioning of the new MUN Explorer AUV, built by ISE, considerable thought was given to the options available for insurance of the vehicle. Discussions were held with a St. John's insurance broker and with Memorial University's risk management group to obtain costs of coverage. Two attempts were made (unsuccessfully) to apply for operating funding for the vehicle and in both cases the high cost of insurance coverage for the AUV was cited as one reason for the "decline to fund" decision on these applications.

To set the scene for the extent of coverage required: initial operations extending at least over the first year were planned to be at inshore locations, launch and recovery were to be from a pier using a dockside crane, and the AUV operations were to be within $5 \mathrm{~km}$ and line of sight of the launch point. Members of the core operating team are university employees, not students, who have attended training in operation of the AUV with the manufacturer, as well as gaining other experience with well known experienced AUV operating teams. The AUV will be followed during its missions by a tracker boat that will remain in radio contact with the AUV operations control station. The tracker boat will fly a "diver/equipment in the water" flag. The operations are to be in coastal Newfoundland where inshore traffic is relatively low.

Using this operating scenario a tentative rate of $6 \%$ of capital cost per year was obtained for coverage from a commercial broker. However, despite this favourable 
quotation, as operating funding was not available for full commercial insurance coverage for the vehicle and its operations, other options had to be considered and implemented. Memorial University provides liability coverage for all operations, both on land and the ocean, that are involve the research activities of its personnel and students. In addition, under its general policy, Memorial has provided insurance coverage for large items, including ocean equipment and sensors, although a deductible of $\$ 250,000$ has applied. Note that Memorial has active oceanography, ocean science and ocean engineering programmes that have been in operation since the inception of research at the University and so has considerable experience with at-sea missions including coverage for vessels.

The resulting direction is to make use of the University's general policy for liability for research activities and as much coverage as possible for the vehicle itself from this source. The aim will be to "act as a prudent uninsured" and to build up a replacement/recovery fund to address losses. Such accumulation and carry over of funding can be difficult in a public sector organisation. At a minimum, the fund will need to address the scope of operations to track and recover the vehicle using the hiring of commercial divers, $\mathrm{ROV}(\mathrm{s})$ and support vessel(s).

The questions that arise include: Can we withstand the risks of operating without full commercial insurance? What are the risks of losing the vehicle and can it be recovered if lost? What are the risks of a total loss and can we carry that risk? The answer to the first is that we have no choice, and to the second that we intend to minimise the risks through a gradual build up of our operating experience in as benign an operating environment as possible in the first years. Losing the vehicle would shut down our AUV 
programme almost completely, although we do have a less capable second vehicle that was developed partially in-house and partly with assistance from ISE.

Eventually our operations will progress to much higher risk missions and we will have to continually update our approach to insurance coverage to ensure that our operations remain viable. Present practical commercial insurance rates for AUVs vary approximately in the range 6-20\% of capital cost per year depending on the risks involved, the type of operation, the experience of the operating team, etc. Rates are much more in high-risk situations, but operators have to assess whether the science answers found are worth taking the risks.

\section{Conclusions}

Insurance is one important element in the risk management strategy for the owners and operators of AUVs. For established users, operating in benign, open water environments purchasing insurance can represent value for money. For new users, obtaining insurance can be costly while building up a track record and training staff. In these cases, alternative, or complementary risk management strategies may be needed.

All of the case studies point to the need for open and constructive dialogue between users/manufacturers and insurance professionals - especially with underwriters. AUV technology is still evolving, and there are significant differences between outwardly similar vehicles that need to be understood by those considering and bearing risk. Where there has been effective communication, the case studies show that efficacious risk management solutions, including insurance, can be reached. 


\section{Acknowledgements and disclaimer}

We are grateful to Keith Broughton and Simon Edwards of Leviathan for engaging in discussions and for helpful comments on our first draft. We thank the Chief Financial Officer of company Y for his frank comments. Otherwise the views expressed here are those of the authors. Potential purchasers of AUV insurance should seek professional advice on their specific requirements.

\section{References}

1. Edwards SRP. (2000). AUVs. How do you insure them? International Ocean Systems Design, 4(1): 10-12.

2. Brown ED. and Gaskell NJJ. (2000). Report on the law, state practice and procedure relating to autonomous underwater vehicles, Society for Underwater Technology, London, UK. 200pp + appendices.

3. Brown ED. and Gaskell NJJ. (2001). Questions and answers on the law, state practice and procedure relating to autonomous underwater vehicles, Society for Underwater Technology, London, UK. 82pp.

4. Griffiths G., Millard NW., McPhail SD., Stevenson P. and Challenor PG. (2003). On the Reliability of the Autosub Autonomous Underwater Vehicle. Underwater Technology, 25(4): 175-184.

5. Strutt J. (2006). Report of the inquiry into the loss of Autosub2 under the Fimbulisen. National Oceanography Centre, Southampton, UK. 39pp. Available as a pdf via http://eprints.soton.ac.uk/41098/ 
6. Ferguson J. (2003). Cargo carrying AUVs. In Griffiths G. (editor) Technology and applications of autonomous underwater vehicles, 217-226. Taylor and Francis, London, UK. 


\section{Figures}

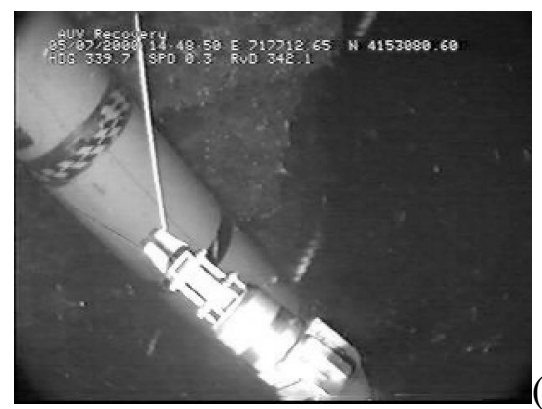

(a) (b)
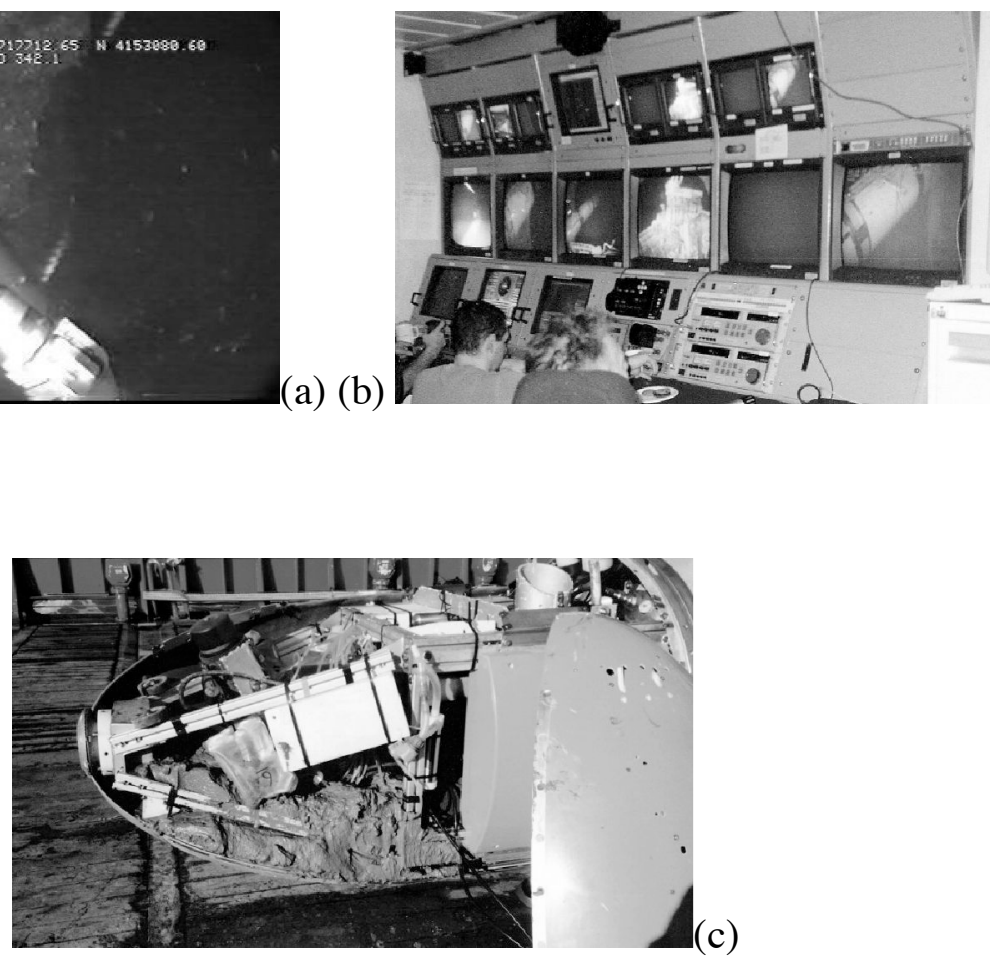

Figure 1 (a) ROV manipulator clearing the recovery line away from the Autosub prior to recovery from under an overhang on an undersea cliff in the Strait of Sicily, (b) The ROV control room of Subsea Viking showing the stranded Autosub on the screens and (c) on recovery, the mud-filled nose of the vehicle (Photographs by Andy Webb with permission). 